\title{
Research Progress of Buton Rock Asphalt in Road Pavement Materials
}

\author{
Qiao Yang ${ }^{1}$ \\ ${ }^{1}$ China Municipal Engineering Central South Design and Research Institute Co., Ltd. Kunming Branch, 650000, Guandu District, \\ Kunming City, Yunnan Province
}

\begin{abstract}
A large number of domestic and international literatures have studied the pavement performance of composite modification of Buton rock asphalt and different asphalt modifiers. It is found that basalt blending can greatly improve the performance in an all-round way, in which high-temperature stability and low-temperature cracking resistance have superimposed effect. Waste rubber powder blending has little overall performance improvement. With diatomite blending the performance can exceed SBS modified asphalt. The research on composite modification of Buton rock asphalt still needs further study.
\end{abstract}

\section{Introduction}

With the rapid development of the national economy, all walks of life are also booming, which brings the growing demand for the transportation industry. Due to the economic development after reform and opening-up, China's road engineering has made great progress. The traffic volume and traffic load increase in a geometric trend year by year. However, in summer, there are high temperature and rains in most areas of our country. These problems have put forward severe tests to the road quality construction in our country.

As one of the important pavement forms of high-grade highway, asphalt pavement has some unavoidable defects, such as cracks, ruts, pits, looseness, etc., which will cause the actual service life of some asphalt pavement to fail to reach the design service life specified in the specification 123 . Therefore, it becomes more and more urgent and important to delay the appearance of early damage phenomenon and improve the service performance of pavement and prolong the service life of pavement, and the best way to solve the problem is to start from the fundamental raw materials.

In terms of materials, researchers are committed to finding new asphalt with better performance. Natural rock asphalt has been widely favored in recent years due to its excellent road performance, simple construction technology, economic and reasonable price and other good compatibility characteristics. Buton rock asphalt (BRA) is produced in Buton Island, Indonesia. Its appearance is black brown granular. The pure asphalt accounts for $22 \%-28 \%$ of the total BRA content, and $72 \%$ - $78 \%$ is called lime mineral. BRA has excellent performance, namely: (1) Due to its high softening point of $160 \sim 175^{\circ} \mathrm{C}$, the softening point of modified asphalt using BRA is also improved. The high temperature stability of BRA mixture is better, and the temperature sensitivity is reduced, which can greatly improve the antirutting performance of asphalt concrete pavement (2) Buton rock modified asphalt is stable because of its good compatibility with base asphalt, so its preparation process is simple and its storage is convenient. (3) Because nitrogen accounts for a large proportion of many elements in BRA, and it is easy to form a large number of stable covalent bond compounds with oxygen in the air, and the compounds in the asphalt agglomerate with each other to form molecular groups with large molar mass, and their resistance to oxygen elements is enhanced. Therefore, the pavement of BRA has strong water loss resistance, which makes asphalt and oxygen elements mor adhesive. (4) Because of the coexistence of rock asphalt with nature in millions of years, the BRA has excellent anti-aging properties. (5) Because BRA is characterized by fine solid particles, it is very convenient to transport and use. In preparation, different methods can be used to prepare modified asphalt according to the actual situation of the equipment, which are dry method and wet method. The dry method can be directly put into use through the pipeline for putting mineral powder, and the wet method can be used to store the prepared modified asphalt in tank. (6) BRA can be used at the same time with other admixtures and polymer modifiers after adjusting the mixing proportion, which can modify various base asphalt.

The improvement effect of BRA on low temperature performance of modified asphalt mixture is not ideal, which affects the overall evaluation of the performance of modified asphalt. Therefore, in order to solve the current situation, many scholars have gradually changed their research direction from the single modification of BRA to the composite modification of BRA and other modifiers. 


\section{COMPOSITE MODIFICATION OF BASALT FIBER AND BRA}

Basalt fiber (BF) is a new type of inorganic environmental protection and high-performance fiber material which can improve the low temperature performance and fatigue resistance of asphalt mixture. However, it has limited ability to improve the high temperature performance and water stability performance of asphalt mixture. The basalt fiber is compounded with BRA.

Table 1 results of rutting test ${ }^{4}$

\begin{tabular}{|c|c|c|c|c|c|}
\hline \multirow{2}{*}{$\begin{array}{l}\text { Types of modified } \\
\text { asphalt }\end{array}$} & \multicolumn{3}{|c|}{$\begin{array}{l}\text { Dynamic stability- } \\
\text { of rutting testt. } \\
\text { (time-mm } \text { t. }^{-1}\end{array}$} & \multirow{2}{*}{$\begin{array}{l}\begin{array}{l}\text { DS average - } \\
\text { value/ } \\
\text { (time-mm-1) }\end{array} \\
1492\end{array}$} & \multirow{2}{*}{ 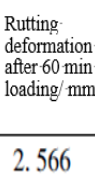 } \\
\hline & 1489 & 1654 & 1332 & & \\
\hline $0.3 \% \mathrm{BF}$ & 2612 & 2978 & 2703 & 2764 & 2.016 \\
\hline $25 \% \mathrm{BRA}$ & 3289 & 3654 & 3564 & 3502 & 1.927 \\
\hline $0.2 \% \mathrm{BF}+25 \% \mathrm{BRA}$ & 6053 & 6409 & 6213 & 6225 & 1.534 \\
\hline $0.3 \% \mathrm{BF}+20 \% \mathrm{BRA}$ & 6303 & 6243 & 6703 & 6416 & 1.518 \\
\hline $0.4 \% \mathrm{BF}+15 \% \mathrm{BRA}$ & 5983 & 5831 & 6012 & 5942 & 1.637 \\
\hline $4.5 \%$ SBS & 4494 & 4872 & 4542 & 4636 & 1.793 \\
\hline
\end{tabular}

Table 2 low temperature bending test results ${ }^{4}$

\begin{tabular}{cccc}
\hline $\begin{array}{c}\text { Types of modified } \\
\text { asphalt }\end{array}$ & $\begin{array}{l}\text { Flexural tensile. } \\
\text { strengthMPa }\end{array}$ & $\begin{array}{l}\text { Maximum } \\
\text { bending tensile. } \\
\text { strain } \mu \varepsilon^{4}\end{array}$ & $\begin{array}{l}\text { Stiffness } \\
\text { modulus MPa }\end{array}$ \\
\hline Base asphalt & 8.57 & 2279.35 & 3760 \\
$0.3 \% \mathrm{BF}$ & 11.74 & 2809.43 & 3823 \\
$25 \% \mathrm{BRA}$ & 11.17 & 2361.64 & 4306 \\
$0.2 \% \mathrm{BF}+25 \% \mathrm{BRA}$ & 12.41 & 3709.48 & 3345 \\
$0.3 \% \mathrm{BF}+20 \% \mathrm{BRA}$ & 13.17 & 4268.32 & 3086 \\
$0.4 \% \mathrm{BF}+15 \% \mathrm{BRA}$ & 12.64 & 4165.47 & 3034 \\
$4.5 \% \mathrm{SBS}$ & 11.79 & 4271.38 & 2760 \\
\hline
\end{tabular}

Table 3 water stability test results ${ }^{4}$

\begin{tabular}{|c|c|c|c|c|}
\hline \multirow{2}{*}{$\begin{array}{l}\text { Types of modified } \\
\text { asphalt }\end{array}$} & \multicolumn{2}{|c|}{ Immersion:Marshall test } & \multicolumn{2}{|c|}{ Freeze thaw splitting test } \\
\hline & $\begin{array}{l}\text { After } \\
\text { immersion. } \\
\text { MS } / \mathrm{kN}^{4}\end{array}$ & $\begin{array}{c}M S_{0} / \\
\%\end{array}$ & $\begin{array}{l}\text { Spliting strength- } \\
\text { before frezeze } \\
\text { thaw } M \mathrm{Pat}^{4}\end{array}$ & $\begin{array}{c}\text { TSR I } \\
\%\end{array}$ \\
\hline Base asphalt & 7.59 & 82.1 & 0.872 & 80.8 \\
\hline $0.3 \% \mathrm{BF}$ & 9.65 & 87.5 & 1.032 & 86.4 \\
\hline $25 \% \mathrm{BRA}$ & 10.77 & 93.4 & 1. 111 & 91.3 \\
\hline $0.2 \% \mathrm{BF}+25 \% \mathrm{BRA}$ & 12.01 & 96.5 & 1.221 & 93.2 \\
\hline $0.3 \% \mathrm{BF}+20 \% \mathrm{BRA}$ & 12.41 & 97.3 & 1.284 & 96.1 \\
\hline $0.4 \% \mathrm{BF}+15 \% \mathrm{BRA}$ & 12.31 & 97.5 & 1.204 & 95.3 \\
\hline $4.5 \%$ SBS & 10.54 & 92.9 & 1. 191 & 91.2 \\
\hline
\end{tabular}

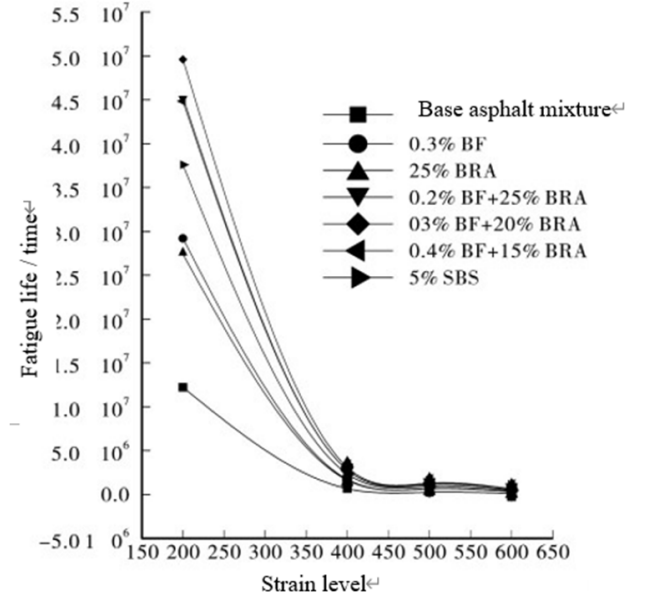

Figure 1 fatigue test result curve ${ }^{4}$

From the above tables and figure, in terms of high temperature stability, compared with single modification, the composite scheme of basalt fiber and BRA can achieve the superposition effect of improving the hightemperature performance of asphalt mixture. In terms of low-temperature crack resistance, the combination of BRA and basalt fiber has a superposition effect on the improvement effect of low-temperature performance of asphalt mixture. In terms of water stability, the water stability of asphalt mixture is improved by pairing BRA with basalt fiber, and the low temperature performance of asphalt mixture improves the water stability of asphalt mixture. In terms of fatigue resistance, basalt fiber and BRA composite modified asphalt mixture has excellent anti fatigue performance.

\section{COMPOUND MODIFICATION OF CRUMB RUBBER AND BRA}

The advantages of crumb rubber modified asphalt are that it can improve the low-temperature crack resistance, prolong the service life, reduce the noise of driving vehicles, etc., but the adhesive force and water damage resistance of crumb rubber modified asphalt and aggregate are relatively poor. The amount of $15 \%, 20 \%$ and $25 \%$ of Buton rock and the amount of $16 \%, 19 \%$ and $22 \%$ of crumb rubber are used for the compound.

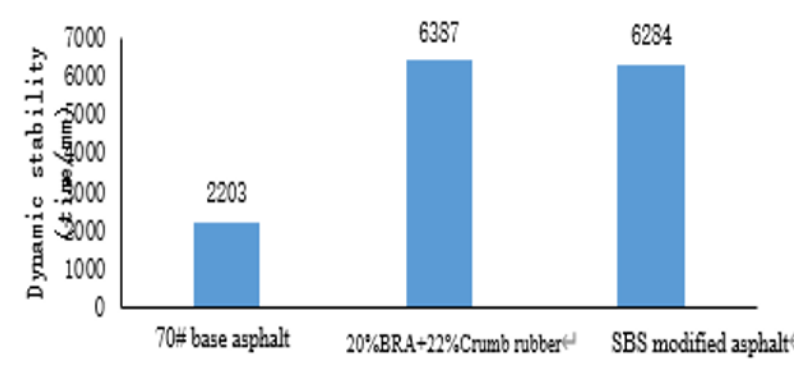

Figure 2 High temperature rmance test results ${ }^{5}$ 


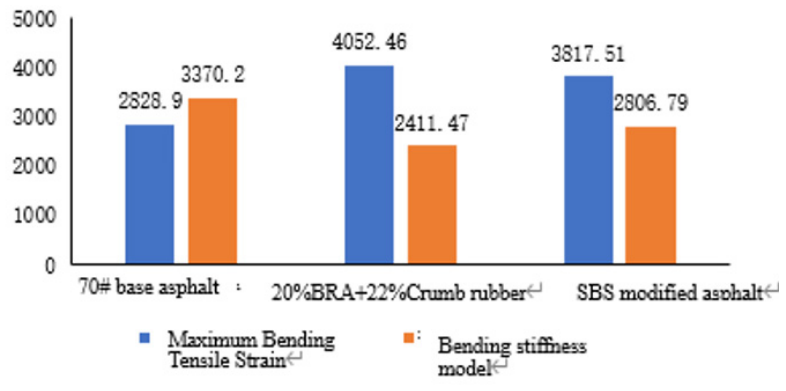

Figure 3 Test results of low temperature cracking resistance ${ }^{5}$

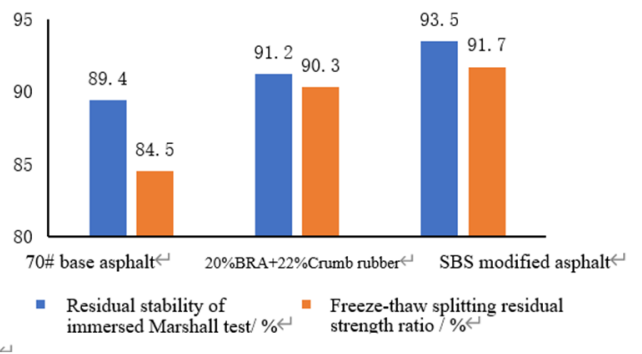

Figure 4 Test results of aging resistance ${ }^{5}$

BRA-crumb rubber composite modified asphalt mixture is 2.9 times higher than the base asphalt. Adding the combined amount of $20 \%$ BRA $+22 \%$ crumb rubber can significantly reduce the rutting deformation of asphalt at high temperature and greatly improve the resistance to permanent deformation of the mixture. The combined mixing can significantly improve the low temperature deformation resistance of ordinary asphalt mixture and enhance the low temperature cracking resistance of the mixture. The performance improves the flexibility of the asphalt mixture and the ability to release stress. The combination blending enhances the adhesion between asphalt and aggregate and improves the water stability.

\section{COMPOUND MODIFICATION OF CRUMB RUBBER AND BRA}

Diatomite is a biogenic siliceous sedimentary rock with abundant micro-special porous structure and large specific surface area. Its performance improvement to asphalt mixtures is mainly manifested in water stability and low temperature cracking resistance. The composite test of diatomite and BRA was carried out.

It is found from the article ${ }^{6}$ that in terms of the high temperature stability, the high temperature shear resistance of asphalt mixture can be significantly improved and its temperature sensitivity reduced by using this compound scheme. As for the low temperature crack resistance, when $14 \%$ diatomite $+20 \%$ BRA is mixed, the low temperature performance of the mixture can be improved to the maximum extent and even exceeds SBS.
In terms of water stability, this compound scheme has excellent performance in water stability of the mixture, stronger than SBS.

\section{CONCLUSIONS}

BRA is a relatively inexpensive modifier with broad application prospects. Reseach and practice have proven its single modified asphalt can greatly improve high temperature performance and fatigue resistance, but its low temperature performance and water stability are still the main disadvantages after modification. The research on modifiers compounded with them is more and more extensive, but some only on asphalt, some on asphalt mixtures, and there is the possibility and necessity of further research.

With the development of transportation, the pavement load is more and more large and the pavement condition is more and more complicated. BRA will be paid more and more attention and researched by scholars, and will certainly be better and more used in pavement materials of our country.

\section{References}

1. Mouillet V, Farcas F, Besson S . Ageing by UV radiation of an elastomer modified bitumen[J]. Fuel, 2008, 87(12):2408-2419.

2. Zhang F, Yu J , Wu S . Effect of ageing on rheological properties of storage-stable SBS/sulfur-modified asphalts[J]. Journal of Hazardous Materials, 2010, 182(1-3):507-517.

3. Vargas X A, Afanasjeva N, M. Álvarez, et al. Asphalt rheology evolution through thermo-oxidation (aging) in a rheo-reactor[J]. Fuel, 2008, 87(13):3018-3023.

4. Wang Cuihong. Performance and modification mechanism of basalt fiber and Boutonite asphalt composite modified asphalt mixture[J]. Highway Engineering, 2018, v.43;No.188(01):106-113

5. Qiao Yang. Research on road performance of compound modified asphalt and mixture of Butonite asphalt and 40 mesh rubber powder[D]. 2019.

6. Wang Zhenhong.Composition optimization of diatomite/BRA rock asphalt composite modified asphalt and study on its mixture performance[J].New Building Materials,2020,47(08):27-31.

7. Zeng Menglan,Xia Yinglin,Zhu Wenqiang,Zhou Jie.The correlation between conventional and rheological properties of bio-asphalt, rock asphalt and composite modified asphalt[J].Journal of Hunan University (Natural Science Edition),2019,46(11):131- 136. 